Revue d'histoire de l'Amérique française

ZAS REVUE D.HISTOIRE DE L'AMÉRIQUE FRANÇAISE

\title{
Le rôle de Lionel Groulx comme éveilleur de conscience nationale de ses compatriotes
}

Joanne Bourassa

Volume 32, numéro 3, décembre 1978

Lionel Groulx, $100^{\mathrm{e}}$ anniversaire de sa naissance, 1878-1978

URI : https://id.erudit.org/iderudit/303720ar

DOI : https://doi.org/10.7202/303720ar

Aller au sommaire du numéro

Éditeur(s)

Institut d'histoire de l'Amérique française

ISSN

0035-2357 (imprimé)

1492-1383 (numérique)

Découvrir la revue

Citer cet article

Bourassa, J. (1978). Le rôle de Lionel Groulx comme éveilleur de conscience nationale de ses compatriotes. Revue d'histoire de l'Amérique française, 32(3), 449-454. https://doi.org/10.7202/303720ar d'utilisation que vous pouvez consulter en ligne.

https://apropos.erudit.org/fr/usagers/politique-dutilisation/ 


\section{LE RÔLE DE LIONEL GROULX COMME ÉVEILLEUR DE CONSCIENCE NATIONALE DE SES COMPATRIOTES*}

JoANNE BoURASSA

Collège de Valleyfield Valleyfield

«Je me souviens... d'un sauveur nommé Lionel Groulx »

Que Lionel Groulx soit avec nous. Et avec son esprit. Grâce à une foi inlassable dans une cause désormais séculaire, il entre dans la postérité. Rien n'aurait pu infléchir son dessein, celui-là même qu'il désirait que tout un peuple nourrisse. Misant tout sur l'ethnocentrisme, il réalise certaines conversions d'importance. Qui est-il donc, aux yeux du présent, pour mériter, pour attirer l'attention? Lionel Groulx n'est-il pas l'un des architectes de l'évangélisation nationale de notre peuple, un des artisans de la sauvegarde de notre race, d'un fait que l'on peut croire dorénavant perdurable sur le sol québécois, le Fait français? Pour le savoir véritablement, nous nous remémorerons son cheminement, son passage parmi nous. Dans son cas, son chemin de Damas était tout trouvé. Investi d'une mission, il serait sauveur, le sauveur de notre race, il ne pouvait contrarier sa vocation. Et, comme il ne pouvait envisager un avenir meilleur sans une maîtrise du passé, il découvre, étudie et transmet le message historique, sa portée capitale. Ce message, il l'adressera à des groupements, des disciples, des apôtres, à cette élite sur les épaules de laquelle reposera aussi la propagation de la bonne nouvelle et la défense de nos droits français. Il nous quittera donc en nous léguant quelques commandements bien contemporains et une profession de foi peu commune qui doivent se perpétuer.

* Ce travail a obtenu le 2e prix au collégial, dans le cadre du Concours LionelGroulx, 1978, soit $\$ 600$. 
Par amour pour son pays, pour sa petite patrie, Lionel Groulx affirme qu'il a rêvé grand, désespérément grand. Voilà sans doute pourquoi il subsiste aujourd'hui encore des traces indélébiles de son oeuvre. Dès le début du siècle, un prophète nous est né. Avec l'allure d'une révélation, Groulx se voyait chargé d'une mission. Il avait la foi dans la survie de notre nation française, un enthousiasme, un don de lui-même pour ce qu'il appelait la "Cause" et il voulait ardemment les transmettre. De tout son être émanait cette fierté d'être de souche française, cette conscience claire d'appartenir à une race de qualité qui avait droit de cité. Groulx respectait et subissait l'influence d'un Garneau, d'un Tardivel et de leurs idées face aux Canadiens français, à leur importance "car pour lui la réalité transcendante à laquelle il jura fidélité c'est le Canada français et non le Canada "1. Cette réalité, il devait la répandre dans notre monde français pour que naisse une race fidèle à sa cause, à son avenir, au salut de son pays, de sa culture, de son ethnie, une race imbue de sens national.

Pour remplir sa mission, pour que son témoignage résonne pour des générations à venir, il fera renaître l'histoire nationale. Elle sera, selon lui, ce catéchisme des croyances et de la morale patriotique qu'il prêchera pour effectuer la conversion, le réveil d'un peuple à sa propre cause. Il trie l'ivraie du bon grain pour prouver à ses compatriotes que vivre en français n'implique ni chimère, ni résignation à la médiocrité, ni infériorité. Prédicateur de la parole historique, il dénoncera notre servitude, notre tendance à l'autodénigrement, nos déformations mythiques. Il nous confie que ce catéchisme, cette histoire est "magistra vitae", maîtresse de vie. Le présent de toutes les époques est non seulement la suite chronologique du passé, il en est aussi le produit. Fernand Dumont a contribué à clarifier cette vision que Groulx se fait de l'histoire.

Pour Groulx, l'histoire comporte des «leçons » parce qu'elle est un milieu de l'homme, la genèse d'où il tire sa forme et donc les axes de sa continuité. ${ }^{2}$

D'ores et déjà, l'éclosion d'un sentiment patriotique généralisé nécessitera sa compréhension, sa contribution. Certains versets de cette bible nationale provoqueront des retentissements profonds.

I Jean-Pierre Gaboury, Le Nationalisme de Lionel Groulx (Ottawa, 1970), 115.

2 Maurice Filion, dir., Hommage à Lionel Groulx (Leméac, Montréal, 1978), 72. 
Notre guide nous souligne alors le magistère de l'histoire; vestiges presqu'estompés, tendances grossières, instincts pusillanimes peuvent faire place à la conscience, à l'idéal, à la volonté. Groulx retrouve cette volonté de survivance française dans le choix effectué par nos ancêtres. Entre se laisser absorber rapidement par la race du conquérant ou se perpétuer comme groupe ethnique autonome, ils optèrent pour la survie. Cette option, cette voie tracée par nos prédécesseurs doit régir, orienter nos actions.

Prenons à titre d'exemples la Conquête anglaise de 1760 et la Confédération de 1867. Groulx réhabilite la cause française dans le cadre de ces deux événements. Olivar Asselin se plaît à nous dire justement que Lionel Groulx, le premier, a mis en doute les bienfaits du régime britannique. À l'admiration inconditionnelle de ses aînés pour celui-ci, il oppose un sérieux sens critique. La Conquête est un cataclysme qui pèse sur notre peuple, qui frappe les Canadiens français d'ostracisme dans les domaines civil et politique. Ils héritent, de même, d'un penchant à la soumission, d'une âme de vaincus, d'un sentiment d'infériorité face aux conquérants dont ils ne se départiront pas facilement. En somme, elle causa un tort immense à notre nation. Chaque génération depuis $1760 \mathrm{a}$ donc dû mériter de rester française. On a même crié, dans certains cas, au scandale devant ce pays français refusant un visage anglais. La Confédération, une fois l'euphorie passée, devait en être le prolongement. Ce pacte confédératif, aux yeux de Groulx, introduisait la dualité nationale, le combat. Car il viole nos droits, jette de la poudre aux yeux et fait miroiter l'utopie du bilinguisme. Lionel Groulx s'acharne donc à comprendre tous ces faits, à creuser le passé pour y découvrir des leçons susceptibles de produire un réveil plus vigoureux du sentiment national de son peuple. Il voyait clair. $\mathrm{Au}$ Manitoba et dans les territoires du Nord-Ouest des textes garantissaient l'usage de la langue française et les droits de l'école confessionnelle, mais vingt ans au plus après leur insertion dans la constitution manitobaine, on pouvait dire "Que de mots, que de maux!» Des hommes doivent se constituer défenseurs de ces idées. Porte-étendard de la résistance, Groulx allait redonner aux francophones le sens de leur fierté nationale et de l'attachement à l'histoire. Conscients de ce qui les précédait, ils pourraient avancer. Il y avait de l'avenir. Libérer les Canadiens français de leur défaitisme, 
dénoncer une politique assimilatrice trop généralement acceptée, c'était l'entreprise de Groulx, son pari. Après tout, notre bible nationale regorgeait de richesses! Les Canadiens français avaient tous le droit de vivre le front haut, debout, il fallait qu'ils le sachent, qu'ils en soient conscients.

Lionel Groulx allait se choisir des disciples pour que la bonne nouvelle soit répandue aux quatre coins de la nation française, que cette bonne nouvelle, ce message historique lui survive, et en addition à cela il allait publier plusieurs volumes dont une histoire du Canada français, des brochures et des pamphlets. Sa méthode d'approche, son action est sans contredit essentiellement pédagogique. Il a une confiance éperdue dans la jeunesse : il recrutera chez elle de bons apôtres. Au Séminaire de Valleyfield, les jeunes Jules Fournier, Maxime Raymond... souscrivent à son nationalisme. Groulx fondera un mouvement d'action catholique qui créera soupçons et méfiance à son égard. Le prophète des temps modernes se heurtait à des incompréhensions. Mgr Emard lui reprochait «un esprit dangereux ". Il conservera pourtant ses idées, ce besoin, cette nécessité de la formation d'une élite, de chefs, d'apôtres. Laissons-le parler :

Former un seul apôtre, disais-je parfois à mes plus grands, lancer dans la vie l'un de ces hommes merveilleux qui, à son tour, ne manquera pas de susciter une légion d'agissants pareils à lui, où et comment marquer ses limites aux rebondissements infinis d'une telle réussite ?3

En 1915, on lui confie la chaire d'histoire de l'Université de Montréal. Quoi de plus inespéré pour poursuivre son oeuvre! On l'invite à prononcer des séries de conférences, augmentant ainsi son auditoire. D'une façon connexe, L'Action française puis en 1928, L'Action nationale essaieront d'expliquer aux jeunes la nécessité, avant toutes choses, d'un enracinement dans son pays en suscitant un peu partout l'adhésion de défenseurs de la cause française. La Société Saint-Jean Baptiste est, elle aussi, une association dans laquelle Groulx avait mis toute sa confiance. De plus il fonde la Revue d'histoire de l'Amérique française et vers 1948, il donne des cours d'histoire à la radio, synthèse de son Histoire du Canada. Dans le domaine strictement politique, il est l'un des promoteurs de 
l'Alliance Laurentienne, de l'Action Libérale Nationale et du Bloc Populaire avec l'un de ses disciples, Maxime Raymond. Philippe Hamel, à cette époque, sera à ses yeux un intrépide défenseur du nationalisme canadien-français. Son idée de nationalisation de l'électricité lui tient à coeur pour que nous soyons un peu plus «maîtres chez nous ", slogan que lui ravira Lesage en 1962. Mais, à quelques reprises, le mythe des chefs, l'espoir qu'il fondait dans certains hommes l'ont déçu. Avant que trente ans ne se soient écoulés deux hommes l'auront désappointé à divers degrés : Bourassa, pour la forme de plus en plus timorée de son engagement politique, Duplessis pour son opportunisme, son attirance vers le pouvoir, de même que tous les politiciens du Québec qui ne surent faire que la politique d'Ottawa. Cependant, grâce à des cours, à des conférences, à des entrevues accordées, à des conseils prodigués à maintes personnes influentes, à sa volonté de recrutement d'une élite, à des disciples-historiens, tels Guy Frégault et Maurice Séguin, demain nous réserve de ces héros qui vivront d'un idéal : la nation française!

Lionel Groulx a vécu sa profession de foi. Nous aurions pu facilement l'entendre réciter avec une espérance toujours neuve : je crois au nationalisme, je crois à la race française, je crois à la grandeur de notre passé canadien-français, à la création d'un État français en Amérique du Nord, dans la Confédération si possible, à l'extérieur si impossible. Ainsi soit le Fait français. Il ne peut donc nous quitter sans nous léguer des recommandations, des commandements fondamentaux pour que jamais ne disparaisse sur notre territoire une foi de grande qualité dans une race qui doit demeurer à tous prix ancrée solidement.

Quoi qu'il advienne, cette autre solution demeure inéluctable que le jour où le Canada français aura acquis la nette conviction qu'il ne peut, sans l'indépendance, s'épargner le suicide, il n'aura plus qu’à ramasser ses énergies et à faire face au défi. Nulle nation, si petite soit-elle, n'a l'obligation, encore moins le devoir d'accepter le génocide par complaisance pour un plus puissant. ${ }^{4}$

Il nous a indiqué, infatigablement, qu'être français, rester français, c'était même plus que notre droit, c'était notre devoir et notre 
mission. Il nous faut sans cesse penser en termes d'État français, d'une économie que nous devons prendre de plus en plus entre nos mains si nous voulons survivre avec dignité. Groulx était convaincu que les idées se transmettent à condition qu'elles se trouvent des porteurs. Lui, il les a portées. C'est à notre tour, il veut que nous les portions plus loin, avec persévérance.

En mai 1967, Lionel Groulx est décédé. Il laissait derrière lui un peuple de croyants heureux d'avoir appris ce que recèle notre maître le passé, d'avoir été convertis à cette conscience claire, d'avoir retrouvé leur fierté et des apôtres prêts à continuer l'oeuvre d'évangélisation nationale. Car, tout comme son idéal, tout comme le Québec français actuel, Lionel Groulx l'a sans cesse soutenu : «Je suis de ceux qui refusent de mourir ${ }^{5}$." La continuation de son oeuvre est sans aucun doute la plus belle résurrection, riche en promesses d'avenir pour sa petite patrie, pour son peuple. Allons vers notre État français. Nous rendons hommage à Lionel Groulx. 